\title{
The 2,4-D-induced wheat para-nodules are modified lateral roots with structure enhanced by rhizobial inoculation
}

\author{
PERIGIO B. FRANCISCO, JR. ${ }^{1,3}$ and SHOICHIRO AKAO ${ }^{2}$ \\ ${ }^{1}$ Institute of Biology, College of Science, University of the Philippines, Diliman, Quezon City 1101, \\ Philippines; ${ }^{2}$ Laboratory of Nitrogen Fixation, National Institute of Agrobiological Resources, 2-1-2 \\ Kannondai, Tsukuba City, Ibaraki 305, Japan; ${ }^{3}$ Present address: USDA/ARS Plant Physiology and \\ Genetics Research Unit, 331 PABL, University of Illinois, 1201 W. Gregory Drive, Urbana, IL \\ 61801, USA
}

Received 10 June 1992. Accepted in revised form 24 October 1992

Key words: 2,4-dichlorophenoxyacetate, para-nodule, Rhizobium trifolii, structure, Triticum aestivum L., wheat

\begin{abstract}
Nodular outgrowths (para-nodules or $p$-nodules) on the roots of wheat (Triticum aestivum L.) cv. Miskle seedlings were induced by treatment with 0.3 and $0.6 \mathrm{mg} \mathrm{L}^{-1}$ 2,4-dichlorophenoxyacetate (2,4-D). When co-inoculated with Rhizobium trifolii strain ATCC 14480 , more $p$-nodules were formed at these levels and $p$-nodulation occured at $0.1 \mathrm{mg} \mathrm{L}^{-1}$ indicating that inoculation enhances 2,4-D-induced $p$-nodulation. Similar to lateral roots, the $p$-nodules arose from the pericycle opposite the phloem tissues and were free from the cortical cells of the parental root at all stages of development. Structurally, the $p$-nodules exhibited tissue differentiation. They possessed a highly organized central vascular cylinder connected to that of the parent root, an endodermis, a cap, and an apical and lateral meristems. $P$-nodules formed by $2,4-\mathrm{D}$ treatment alone were irregularly lobed due to uncoordinated activity of the apical meristem, while those in the combined 2,4-D and inoculation treatment were more globose. The results of the present study indicate that the 2,4-D-induced wheat $p$-nodules are modified lateral roots, the structure of which is enhanced by rhizobial inoculation.
\end{abstract}

\section{Introduction}

The symbiotic association between the nonlegume Parasponia and rhizobia (Trinick, 1973) and several non-legumes with the actinomycete Frankia (Becking, 1970; Dixon and Wheeler, 1986), the considerable variation in the details of symbiotic interaction and nodule morphology of different legume species (Corby, 1988; De Faria, 1989), and the presence of haemoglobin genes in non-leguminous plants (Appleby et al., 1986; Bogusz et al., 1988; Martin and Dowd, 1986), suggest that symbiotic nitrogen fixation may be extended to non-legumes. The transfer of the nif genes together with others necessary for functional nitrogen fixation into chloroplasts is believed to be the best strategy to achieve this prospect (Postgate, 1987), but the complexity of gene regulation remains as a great hindrance to achieving a functional nitrogen-fixing transgenic system (Quispel, 1991). In recent years, however, several novel approaches to nodulate nonlegumes have been developed. These include the engineering of new inoculant rhizobia, inoculation with Rhizobium sesbania mutants or rhizobial isolates of Parasponia, exposure to magnetic field, and treatment of seedlings with cell walldegrading enzymes or with growth regulators 
including the synthetic herbicide 2,4-dichlorophenoxyacetate (Cocking et al., 1990; Kennedy and Tchan, 1992). Among these techniques, 2,4-D treatment combined with inoculation with Azospirillum, a free-living nitrogenfixer closely associated with grasses including wheat, appears to be the most successful so far, as indicated by high acetylene reduction rate which is apparently linked to photosynthesis (Tchan et al., 1991; Zeman et al., 1991).

Of relevance to the attempts to make the 2,4-D-induced nodular structure (called 'paranodule' or ' $p$-nodule' by Kennedy et al., 1990) a functional nitrogen-fixing system, is an understanding of its origin, development, and structure. While the $p$-nodules strikingly resemble legume nodules externally, they are presumed to be lateral roots (Bender et al., 1990; Kennedy and Tchan, 1992). To the authors' knowledge, there is no published evidence proving this. The present paper examines and compares the origin and structure of the 2,4-D-induced $p$-nodules in uninoculated and rhizobia-inoculated wheat seedlings.

\section{Materials and methods}

\section{Plant and bacterial culture}

Seeds of wheat (Triticum aestivum L.) cv. Miskle (a gift from Dr Ivan $\mathrm{R}$ Kennedy, Univ. of Sydney) were dehulled, surface-sterilized with $70 \%$ ethanol $(20 \mathrm{~min})$ followed by $3 \%$ sodium hypochlorite $(3 \mathrm{~min})$ and 5 washes with sterile deionized water at $1 \mathrm{~min}$ intervals. Sterile seeds were then sown on sterile $1 \%$ agar in potato broth, and germinated in the dark. Uncontaminated 5-day-old seedlings were transferred into transparent plastic jars with cotton-plugged lids at 5 seedlings per jar. The growth medium used was prepared by dissolving agar $(1 \%, \mathrm{w} / \mathrm{v})$ in sterile half-strength $\mathrm{N}$-free nutrient solution (Akao and Kouchi, 1989) to which was added 2,4-dichlorophenoxyacette (2,4-D) solution (kept as a stock at $1 \mathrm{mg}$ per $\mathrm{mL}$ in ethanol) to a final concentration of either $0,0.1,0.3$, or $0.6 \mathrm{mg} \mathrm{L}^{-1}$, and then sterilized by autoclaving. The seedlings were either immediately inocu- lated with a 5-mL suspension of Rhizobium trifolii strain ATCC 14480 (obtained from the US Department of Agriculture, Beltsville, MD), or $5 \mathrm{~mL}$ of sterile deionized water was added. The rhizobia used were cultured to late log phase in yeast-mannitol broth in flasks at $28^{\circ} \mathrm{C}$ in darkness with vigorous shaking $(120 \mathrm{rpm})$, collected by centrifugation $(8000 \mathrm{rpm}, 20 \mathrm{~min}$, $4{ }^{\circ} \mathrm{C}$ ), then washed and adjusted to a density of $10^{9}$ cells $\mathrm{mL}^{-1}$ with sterile half-strength Fahraeus medium. Seedlings were kept in an environmentally-controlled growth chamber having a day/ night temperature of $25 / 22^{\circ} \mathrm{C}$, and a photosynthetic photon flux at the surface of the jars of approximately $500 \mu \mathrm{mol} \mathrm{m}{ }^{-2} \mathrm{sec}^{-1}$ provided by 8 halide lamps for $14 \mathrm{~h}$ daily. At 21 days after transplanting, the plants were harvested, and root morphology and $p$-nodule formation were examined. Only distinct, more or less rounded protuberances at the surface of the lateral root, as seen by the naked eye, were scored as visible $p$-nodules. Acetylene reduction activity of the $p$-nodules was tested by incubating the whole $p$-nodulated seedlings with $10 \%$ acetylene gas for $1 \mathrm{~h}$ in flasks fitted with rubber lids. Ethylene was assayed from $0.5-\mathrm{mL}$ samples injected into a Shimadzu Gas Chromatograph equipped with a hydrogen flame ionizer.

\section{Light microscopic observations}

Root segments, $1 \mathrm{~cm}$ long, were fixed in formalin-acetic acid-alcohol solution for at least $48 \mathrm{~h}$, washed with deionized water, transversely sectioned at $10 \mu \mathrm{m}$ thickness with a rotary microtome after dehydration in a graded alcohol series and embedding in Paraplast, affixed to glass slides, then stained with hematoxylin and safranin. Tissue observation and photography was done on a Nikon Optiphot light microscope. In 2,4-D-treated seedlings, any mass of small cells with darkly staining nuclei and originating from the pericycle of the parental root were considered as $p$-nodule primordia. When the primordia have grown to exhibit distinct tissue differentiation, and have reached the outermost layer of the cortex, or have swollen or partly ruptured the epidermis, they were considered as emerging $p$-nodules. 


\section{Results}

\section{Effects on root morphology and p-nodulation}

Treatment with 2,4-D alone decreased the length but increased the number of the primary lateral roots, these effects being more pronounced at higher levels (Table 1, Figs. 1-4). Even at the lowest concentration of $0.1 \mathrm{mg} \mathrm{L}^{-1}$, the secondary lateral roots were considerably shortened and thickened, some of which were swollen at their tips (Fig. 2). At higher levels, the effects on the secondary laterals were more severe, and $p$-nodules were formed (Figs. 3-5). The roots of seedlings treated with 2,4-D were covered with dense root hairs (Figs. 2-5).

When combined with rhizobial inoculation, the effects of 2,4-D treatment on primary lateral root number and length, and $p$-nodulation were more pronounced (Table 1). With inoculation, even the $0.1 \mathrm{mg} \mathrm{L}^{-1}$ treatment induced $p$-nodulation, the number of $p$-nodules being about twice those of the $0.6 \mathrm{mg} \mathrm{L}^{-1}$-treated uninoculated seedlings. Inoculation caused significant differences in $p$-nodule number among 2,4-D treatments, higher levels consistently inducing significantly more $p$-nodules.

\section{Origin and structure of the p-nodule}

$P$-nodule primordia formed in swollen root regions where the cortical cell were hypertrophied. The primordia of the $p$-nodules, regardless of 2,4-D concentration, and those of the lateral roots originated from the pericycle opposite the phloem tissues and were structurally similar (Figs. 6, 9). They all exhibited a central cylinder, cortical initials, and a distinct root cap. The cortical cells adjacent to the $p$-nodule primordia invariably did not divide. Hence, as in lateral root formation, the parental root cortex did not participate in $p$-nodule formation. In longitudinal sections of considerably shortened roots, adjacent $p$-nodule primordia fused and developed multiple vascular strands all connected to the parent root. In roots treated with $0.6 \mathrm{mg} \mathrm{L}^{-1}$ alone or in combination with inoculant, as many as 6-8 primordia and developing $p$-nodules radiated from the vascular cylinder of the parent root in some transverse sections (Fig. 7).

The $p$-nodule primordia differentiated inside the cortical region of the parental root and gave rise to an emerging $p$-nodule with distinct central vascular cylinder, cortex, epidermis, and root cap (Fig. 8). In contrast, lateral root primordia had no visible vascular tissues even at emergence (Figs. 10, 11). Both the emerging $p$ nodule and lateral root crushed and ruptured the surrounding parental cortical tissue and the epidermis thereby creating cracks on the root surface.

Similar to lateral roots, the $p$-nodules in both inoculated and uninoculated seedlings possessed a distinct epidermis and a highly organized central vascular cylinder (Figs. 12-16). The cortex of the $p$-nodule was composed of about 7-8 columns of parenchyma cells (Figs. 12-14) in contrast to the 3-4 columns in the lateral root (Figs. 15, 16), indicating more anticlinal division

Table 1. Root development and $p$-nodule formation in 21-day-old wheat cv. Miskle seedlings treated with 2,4-D and inoculated with Rhizobium trifolii strain ATCC $14480\left(10^{9}\right.$ cells $\left.\mathrm{mL}^{-1}\right)$ at 5 days after sowing. Mean (SE) of 10 replicates

\begin{tabular}{|c|c|c|c|c|}
\hline Treatment & $\begin{array}{l}2,4-\mathrm{D} \\
\text { conc. } \\
\mathrm{mg} \mathrm{L}^{-1}\end{array}$ & $\begin{array}{l}\text { Primary } \\
\text { lateral root } \\
\text { (PLR)/plant }\end{array}$ & $\begin{array}{l}\text { Mean PLR } \\
\text { length } \\
(\mathrm{cm})\end{array}$ & $\begin{array}{l}\text { Visible } \\
p \text {-nodules/ } \\
\text { plant }^{\text {a }}\end{array}$ \\
\hline Uninoculated & $\begin{array}{l}0.0 \\
0.1 \\
0.3 \\
0.6\end{array}$ & $\begin{array}{l}4.33(0.21) \\
5.50(0.45) \\
6.05(0.37) \\
6.50(0.44)\end{array}$ & $\begin{array}{r}23.01(1.84) \\
7.46(0.75) \\
2.98(0.16) \\
2.11(0.16)\end{array}$ & $\begin{array}{l}0 \\
0 \\
2.5(0.3) \\
3.5(1.3)\end{array}$ \\
\hline $\begin{array}{l}R . \text { trifolii } \\
\text { ATCC } 14480\end{array}$ & $\begin{array}{l}0.0 \\
0.1 \\
0.3 \\
0.6\end{array}$ & $\begin{array}{l}5.50(0.43) \\
6.20(0.34) \\
7.29(0.39) \\
7.75(0.39)\end{array}$ & $\begin{array}{r}25.35(2.29) \\
5.52(0.48) \\
1.87(0.13) \\
1.66(0.08)\end{array}$ & $\begin{array}{l}0 \\
6.4(0.4) \\
13.3(2.3) \\
34.2(8.0)\end{array}$ \\
\hline
\end{tabular}

${ }^{a}$ Observed with the naked eye. 

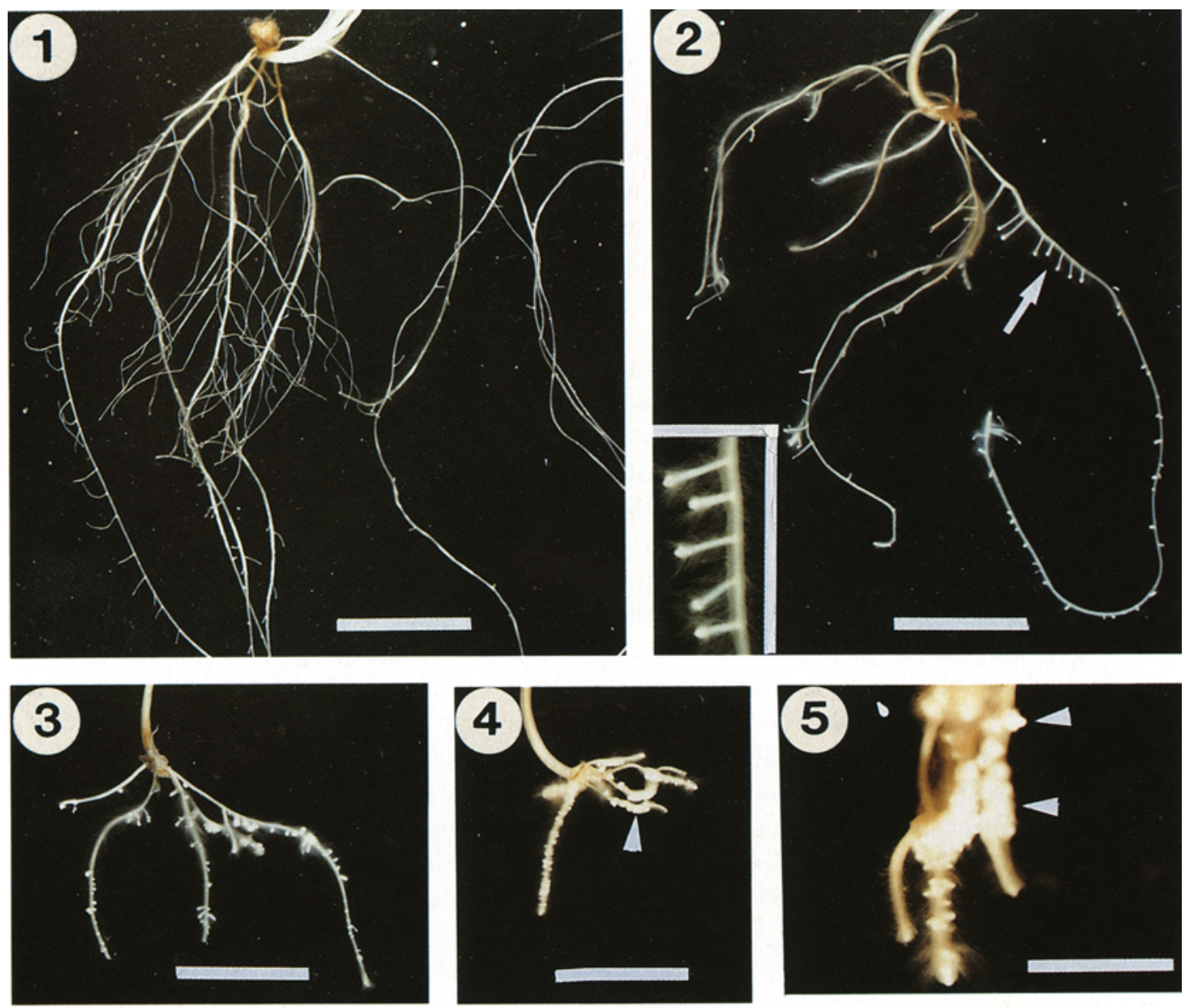

Figs. 1-5. Effects of 2,4-D treatment on wheat root morphology.

Figs. 1-4. Changes in secondary lateral roots with 2,4-D treatment. Scale bar: $2 \mathrm{~cm}$. The secondary lateral root which are long and fibrous in the control (Fig. 1), are markedly shortened at $0.1 \mathrm{mg} \mathrm{L}^{-1}$ 2,4-D (Fig. 2), the longer ones having bulbous tips (arrow and inset), and are further shortened and more closely spaced at $0.3 \mathrm{mg} \mathrm{L}^{-1}$ (Fig. 3) and more notably at $0.6 \mathrm{mg} \mathrm{L}^{-1}$ (Fig. 4), many becoming ovoid-shaped nodular structures, the $p$-nodule (arrow head).

Fig. 5. Magnified root portions bearing $p$-nodules (arrow heads) induced by $0.6 \mathrm{mg} \mathrm{L}^{-1} 2,4-\mathrm{D}$. Scale $b a r: 0.5 \mathrm{~cm}$.

in the former than in the latter. The dome shaped $p$-nodules apparently resulted from radial cell expansion and active cell proliferation from meristematic tissues close to the terminal meristem. At the tip of the $p$-nodule was a structure that exhibited marked resemblance to the root cap. At higher 2,4-D levels, the $p$-nodule developed a number of lateral meristems. In older $p$-nodules, notably those of uninoculated seedlings, the epidermis sloughed off as cells proliferated from the actively dividing apical and adjacent lateral meristems.

The above features are common to all $p$ nodules regardless of treatment. The basic difference between the $p$-nodules in uninoculated and inoculated seedlings was that, in the former, the $p$-nodules were irregularly lobed even before emergence (Fig. 12). This irregular lobing was associated with unequal number and varying sizes of cell at different regions of the distal portion of the $p$-nodule. In contrast, the $p$ nodules in inoculated seedlings were globose, lobing being virtually non-cxistent (Figs. 13 and 14).

\section{Discussion}

The relative ease in inducing $p$-nodule formation through 2,4-D treatment, regardless of inoculation, in our study, supports the idea that $p$ - 

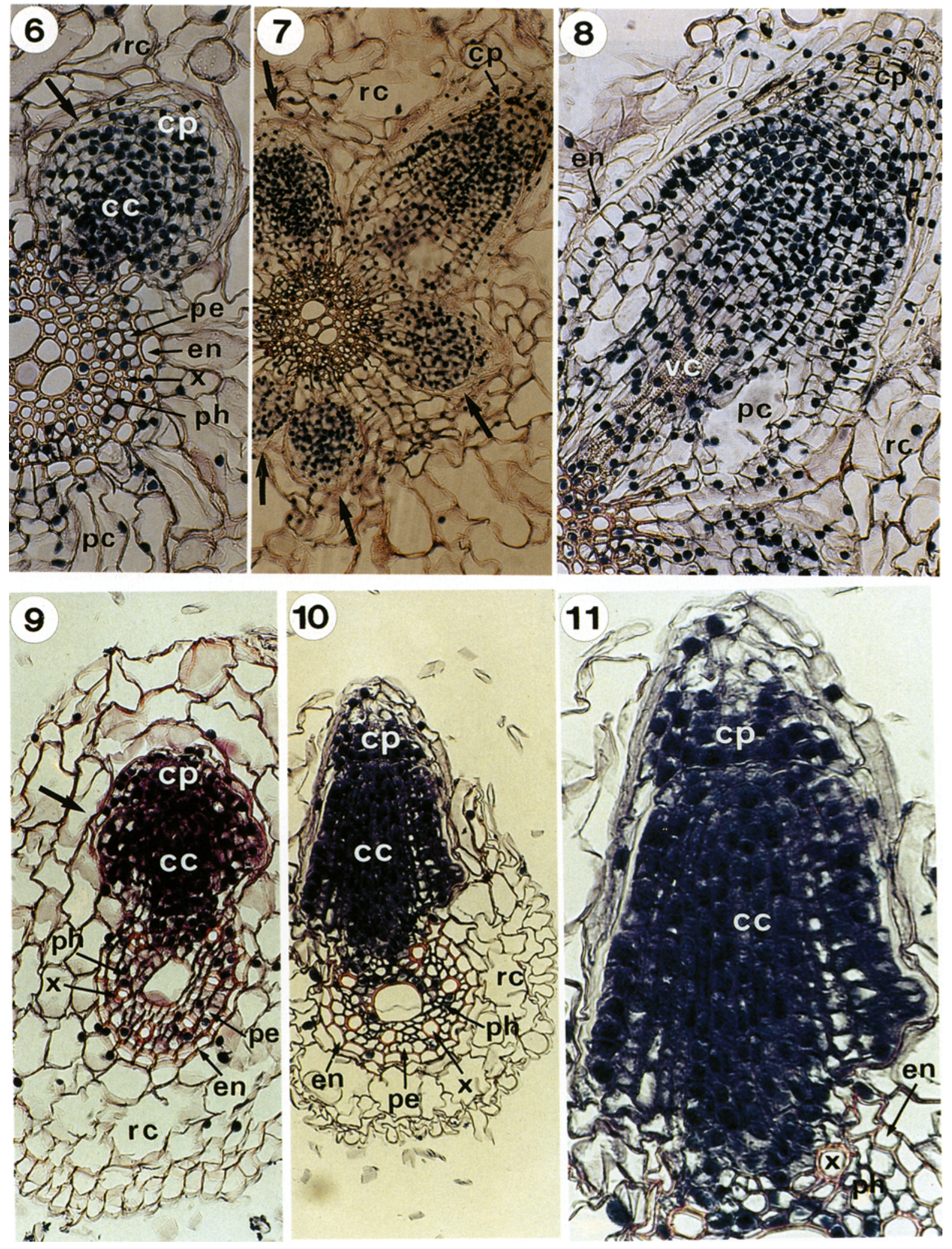

Figs. 6-11. Origin and structure of $p$-nodule (Figs. 6-8) and developing lateral root (Figs. 9-11) in wheat. All are $10 \mu \mathrm{m}$ transverse sections stained with hematoxylin and safranin. Fig. 6. A p-nodule primordium (arrow) arising from the pericycle region opposite the phloem of roots. $\left(0.3 \mathrm{mg} \mathrm{L}^{-1} 2,4-\mathrm{D}\right) . \times 400$. Fig. 7 . Root section with several $p$-nodule primordia (arrows) radiating from the stele of the parental root. $\left(0.6 \mathrm{mg} \mathrm{L}^{-1} 2,4-\mathrm{D}\right)$. $\times 200$. Fig. 8 . A pre-emergence $p$-nodule exhibiting advanced stages of tissue differentiation. $\left(0.6 \mathrm{mg} \mathrm{L}^{-1} 2,4-\mathrm{D}\right) . \times 400$. Fig. 9 . A latcral root primordium (arrow) initiated in the pericycle opposite the phloem. $\times 200$. Fig. 10. Emerged lateral root showing no distinct tissue differentiation. $\times 200$. Fig. 11. Magnified view of the lateral root shown in Figure $10 . \times 400$. (cc: central cylinder, cp: cap, en: endodermis, pc: $p$-nodule cortex, pe: pericycle, ph: phloem, rc: parental root cortex, vc: vascular cylinder, $x$ : xylem). 



Figs. 12-16. Structural comparison between the lateral root of the control and p-nodules of seedlings treated with 2,4-D alone or in combination with thizobial inoculation. All are $10 \mu \mathrm{m}$ thick transverse section stained with hematoxylin and safranin. Fig. 12 . $P$-nodules of $0.6 \mathrm{mg} \mathrm{L}^{-1}$ 2,4-D-treated seedling exhibiting tissue differentation and irregular lobing (arrows). $\times 100$. Fig. 13 . Newly-emerged globose $p$-nodules induced by the combined $R$. trifolii strain ATCC 14480 inoculation and $0.6 \mathrm{mg} \mathrm{L}^{-1} 2,4-\mathrm{D}$ treatment. Note the absence of the irregular lobing found in $p$-nodules of uninoculated seedlings (Fig. 12) and the distinct row of prominently nucleited epidermal cells. $\times 100$. Fig. 14 . An emerged $p$-nodule of inoculated $0.6 \mathrm{mg} \mathrm{L}^{-1}$-treated seedlings. $\times 100$. Fig. 15. Emerged short lateral root of uninoculated $0.1 \mathrm{mg} \mathrm{L}^{-1} 2,4$-D-treated seedling. $\times 100$. Fig. 16. Normal lateral root (basal portion) of untreated seedlings. $\times 200$. (am: apical meristem, cp: cap, ep: epidermis, $1 \mathrm{~m}$ : lateral meristem, pc: $p$-nodule cortex, rc: parental root cortex, vc: vascular cylinder). 
nodulation per se is a physiological process independent of bacterial action (Kennedy and Tchan, 1992). However, our observation that the $0.1 \mathrm{mg} \mathrm{L}^{-1} 2,4-\mathrm{D}$ treatment induced $p$-nodulation only in the presence of the inoculant indicate that rhizobia inoculation might enhance the 2,4-D-induced $p$-nodulation. Moreover, the globose-shaped $p$-nodules of inoculated 2-4,Dtreated seedlings suggests that the inoculant rhizobia regulate cell proliferation in the $p$ nodules.

The mechanism by which 2,4-D induces nodule-like structures in cereals is largely unknown. It cannot be attributed simply to the auxin-like activity of 2,4-D. Yatazawa et al. (1967) observed heavy callus proliferation on excised rice roots with $2 \mathrm{mg} \mathrm{L}^{-1} 2,4-\mathrm{D}$ treatment but not with IAA at a concentration of up to 100 ppm. Kennedy et al. (1991) and Rolfe et al. (1991) found that while the synthetic auxin NAA and polar auxin transport inhibitors help to establish the conditions necessary for the induction of nodule-like structures, neither can successfully induce nodular structures on wheat. Nishimura and Maeda (1982) observed that 2,4$\mathrm{D}$ treatment alters the position, polarity, and axis of cell enlargement of the lateral root primordia of rice, causing them to develop into callus-like structures. An important finding in our laboratory is that 2,4-D treatment induces in non-nodulating soybean T201 nodule-like deformations, which, in the presence of inoculant rhizobia, develop an infected zone and exhibit nitrogen fixing ability (Akao et al., 1991), indicating that $2,4-\mathrm{D}$ initiates process(es) comparable to that induced by rhizobia in normal nodule formation. Similar processes could be initiated in wheat.

The modifying effects of rhizobia on the 2,4$D$-induced wheat $p$-nodulation, in the form of $p$-nodule induction at $0.1 \mathrm{mg} \mathrm{L}^{-1}$, increased $p$ nodulation of seedlings treated with higher 2,4-D levels, and the absence of irregular lobing of the $p$-nodules, could be associated with the rhizobial production of hormones. A number of studies have shown that rhizobia synthesize phytohormones such as auxin (Kaneshiro and Kwolek, 1985; Wang et al., 1982) and cytokinin (Sturtevant and Taller, 1989) which, together with the endogenous hormones of the host plant, are involved in nodule formation (Bauer et al., 1985; Syono et al., 1976). The involvement of the nod genes in hormone production, however, remains to be demonstrated. The exogenous hormones from the bacteria could cause a hormonal balance that is conducive to a more coordinated or regulated cell proliferation necessary in nodule formation. These results emphasize the complex interaction between the host and the endophyte bacteria during the establishment of symbiotic nitrogen fixing system.

It could not be determined whether or not the inoculant bacteria penetrated the $p$-nodules in the present study. Kennedy et al. (1991) observed the inoculant $R$. astragali in the intercellular spaces of the outer cortical region of wheat $p$-nodules. This was also observed in rice $p$-nodules inoculated with a rhizobial isolate of Parasponia (Francisco and Akao, unpublished). In both cases, 2,4-D could have facilitated bacterial entry into the $p$-nodules by stimulating bacterial production of cellulase as previously found by Terouchi (1990) in R. leguminosarum bv. viciae. Cocking et al. (1990) employed cellulase to degrade the cell wall and probably the middle lamella between epidermal cells of rice roots thereby creating ports of entry for rhizobia to induce nodule formation.

The results of the present study provide evidence to show that the 2,4-D-induced wheat $p$-nodules are modified lateral roots. One indication is that, as 2,4-D concentration in the growth medium increases, secondary lateral roots develop into short, swollen structures with bulbous tips, then into spherical ones that externally resemble legume nodules. Apparently, 2,4-D induces cell enlargement in the entire root and promotes cell proliferation at meristematic region notably at the apex. During cell proliferation, it appears that more anticlinal than periclinal division is initiated as indicated by the greater number of cortical cell layers in the emerging $p$-nodules as compared to those in lateral roots. More convincing evidence is the developmental and structural features which $p$ nodules have in common with lateral roots, i.e., their origin from the pericycle and the presence of highly organized central vascular system, epidermis, and a cap-like structure. The developing $p$-nodule and its primordium, like those of 
the lateral root, remain free of the parental root cortex. The $p$-nodules are, therefore, structurally similar to the functional nodules formed by Rhizobium spp. on Parasponia rugosa B1. (Trinick and Galbraith, 1976) and $P$. andersonnii Planch. (Trinick, 1979), and by Frankia on various non-legumes (Becking, 1970; Dixon and Wheeler, 1986), all of which originate from the pericycle and possess a central vasculature, and are, therefore, modified lateral roots.

Legume nodules in contrast are initiated by cell divisions in the cortex, either in the hypodermis, as in soybean (Calvert et al., 1984), or in the inner cortex, as in alfalfa (Dudley et al., 1987). While legume nodules exhibit morphological diversity (Corby, 1988), they all invariably possess a peripheral vascular system which is not found in the actinorhizas nor in the rhizobialinduced nodules in Parasponia (Sprent, 1989).

The $p$-nodules likewise differ structurally and developmentally from the Alnus pseudonodules induced by cytokinins (Rodrigues-Barrueco and Bermudez de Castro, 1973) and those induced by kinetin in tobacco roots (Arora et al., 1959), both of which originate from the cortex of the parent root, exhibit simple and unorganized vascular strands, and grow as a result of the continued division of the parental root cortex. Similar to our 2,4-D-induced wheat $p$-nodules, in the sense that they are also pericyclic in origin, are the pseudonodules formed in leguminous plants treated with 2-bromo-3,5-dichlorobenzoic acid (Allen et al., 1953). Our wheat $p$-nodules most closely resemble the anatomical modifications of bean roots treated with 2,4-D (Wilde, 1953).

The absence of any detectable acetylene reduction activity in the $p$-nodules inoculated with rhizobia, in our study, indicates that symbiotic nitrogen fixation was not occurring. This was also recently reported by Bender et al. (1990) and Kennedy and Tchan (1992) in rhizobiainoculated wheat $p$-nodules. However, with Azospirillum, Kennedy and Tchan (1991) observed high acetylene reduction activity, indicating that structurally, the $p$-nodule is sufficient for the establishment of a functional nitrogen-fixing system. This is not surprising since, as described above, the general structural features of the 2,4$D$-induced wheat $p$-nodules are similar to those of the functional root nodules of non-legumes, minus the infected region of the cortex. Although the essential features of a true symbiosis are still lacking in the $p$-nodule (Kennedy and Tchan, 1992), a better understanding of the features of the functional root nodules of nonlegumes and/or the engineering of bacteria that can interact favorably with the non-legume host may eventually make $p$-noduled wheat, and perhaps other cereals, nitrogen self-sufficient plants.

\section{Acknowledgements}

P F is grateful to Japan International Science and Technology Exchange Center (JISTEC), Japan Research Development Corporation (JRDC), and National Agriculture Research Center for the STA Postdoctoral Fellowship Award, and to Dr Makie Kokubun for his encouragement and valuable suggestions.

\section{References}

Akao S and Kouchi H 1989 Light microscopic observation of root hair curling of soybean induced by Rhizobium infection. Japan. J. Soil Sci. Plant Nutr. 60, 53--55.

Akao S, Nakata S and Yoneyama T 1991 Formation of nodules on non-nodulating soybean T201 after treatment with 2,4-dichloro-phenoxyacetate. Plant and Soil 138, 207212.

Allen K A, Allen O N and Newman A S 1953 Pseudonodulation of leguminous plants induced by 2-bromo-3,5dichlorobenzoic acid. Am. J. Bot. 40, 429-435.

Appleby C A, Bogusz D, Dennis E S, Dudman W F, Fleming A I, Higgins $\mathrm{T}$ J, Kortt A A, Landsmann $\mathrm{J}$, Peacock W J, Tjepkema J D, Trinick M J, Wittenberg B A and Wittenberg J B 1986 The origin and survival of plant haemoglobin genes. In Australian Institute of Agricultural Science, Occasional Publication 25. Eds. W Wallace and S E Smith. pp 77-78.

Arora N, Skoog F and Allen O N 1959 Kinetin-induced pseudonodulates on tobacco roots. Am. J. Bot. 46, 610 613.

Bauer W D, Bhuvaneswari T V, Calvert H E, Law I J, Malik N S A and Vesper S J 1985 Recognition and infection by slow-growing rhizobia. In Nitrogen Fixation Research Progress. Eds. H J Evans, P J Bottomley and W E Newton. pp 247-253. Martinus Nijhoff, Dordrecht, The Netherlands.

Becking J H 1970 Plant-endophyte symbiosis in non-leguminous plants. Plant and Soil 32, 611-654.

Bender G L, Preston L, Barnard D and Rolfe B G 1990 
Formation of nodule-like structures on the roots of the non-legumes rice and wheat. In Nitrogen Fixation: Achievements and Objectives. Eds. P M Gresshoff, L E Roth, G Stacey and W L Newton. p 825. Chapman and Hall, New York.

Bogusz D, Appleby C A, Landsmann J, Dennis E S, Trinick M J and Peacock W J 1988 Functioning haemoglobin genes in non-nodulating plants. Nature 331, 178-180.

Calvert H E, Pence M K, Pierce M, Malik N S A and Bauaer W 1984 Anatomical analysis of the development and distribution of Rhizobium infections in soybean roots. Can. J. Bot. 62, 2375-2384.

Cocking E C, Al-Mallah M K, Benson E and Davey M R 1990 Nodulation in non-legumes by rhizobia. In Nitrogen Fixation: Achievements and Objectives. Eds. P M Gresshoff, L E Roth, G Stacey and W L Newton. pp 813-822. Chapman and Hall, New York.

Corby H D L 1988 Types of rhizobial nodules and their distribution among the Leguminosae. Kirkia 13, 53-123.

De Faria S M, Lewis G P, Sprent J I and Sutherland J M 1989 Occurrence of nodulation in the Leguminosae. New Phytol. 111, 607-619.

Dixon R O D and Wheeler C T 1986 The symbioses. In Nitrogen Fixation in Plants. pp 25-35. Chapman and Hall, New York.

Dudley M E, Jacobs T W and Long S R 1987 Microscopic studies of cell division induced in alfalfa roots by Rhizobium meliloti. Planta 173, 289-301.

Kaneshiro T and Kwolek W F 1985 Stimulated nodulation of soybeans by Rhizobium japonicum mutant (B-14075) that catabolyzes the conversion of tryptophan to indol-3ylacetic acid. Plant Sci. 42, 141-146.

Kennedy I R, Sriskandarajah S, Yu D, Nie F Y and Tchan Y T $1991 \mathrm{C}_{2} \mathrm{H}_{2}$ reducing para-nodules in wheat: Effects of growth regulators and colchicine. Proc. 9th Aust. Nitrogen Fixation Conf. 9, 78-79.

Kennedy I R and Tchan Y T 1992 Biological nitrogen fixation in non-leguminous field crops: Recent advances. Plant and Soil 141, 93-118.

Kennedy I R, Zeman A, Tchan Y T, New P B, Sriskandarajah S and Nie Y and Tchan Y F 1990 Biological nitrogen fixation and prospects for yield increases in wheat. Trans. 14th Int. Congr. Soil Sci. Kyoto. III, 146.

Martin P G and Dowd J M 1986 Is the gene for haemoglobin widespread among dicotyledons? In Australian Institute of Agricultural Science, Occasional Publication 25. Eds. W Wallace and S E Smith. pp 81-82.

Nishimura S and Maeda E 1982 Cytological studies on differentiation and dedifferentiation in pericycle cells of excised roots. Japan. J. Crop Sci. 51, 553-560.

Postgate J 1987 Prospects for the improvement of biological nitrogen fixation. J. Appl. Bacteriol. Symposium Supplement 85S-91S.
Quispel A 1991 A critical evaluation of the prospects for nitrogen fixation with non-legumes. Plant and Soil 137, $1-11$.

Rolfe, B G, Barnard D, Preston L and Bender G L 1991 Nodule-like structures induced on the roots of nonlegumes. Proc. 9th Aust. Nitrogen Fixation Conf. 9, 7173.

Rodriguez-Barrueco C and Bermudez de Castro F 1973 Cytokinin-induced pseudonodules on Alnus glutinosa. Physiol. Plant. 29, 277-280.

Sprent J I 1989 Which steps are essential for the formation of functional legume nodules? New Phytol. 111, 129-153.

Syono K, Newcomb W and Torrey J G 1976 Cytokinin production in relation to the development of pea root nodules. Can. J. Bot. 54, 2155-2162.

Sturtevant D B and Taller B J 1989 Cytokinin production by Bradyrhizobium japonicum. Plant Physiol. 89, 1247-1252.

Tchan Y T, Zeman A and Kennedy I R 1991 Nitrogen fixation in para-nodules of wheat roots by introduced freeliving diazotrophs. Plant and Soil 137, 43-47.

Terouchi N 1990 Analysis of the early infection process in root nodule formation by Rhizobium strains: Curling of Root Hairs in Heterologous Plants. Ph.D. Diss., Tokyo Univ. Japan. pp 73-91.

Trinick M J 1973 Symbiosis between Rhizobium and the non-legume Trema aspera. Nature 144, 459.

Trinick M J 1979 Structure of nitrogen-fixing nodules formed by Rhizobium on roots of Parasponia andersonii Planch. Can. J. Microbiol. 25, 565-578.

Trinick M J and Galbraith J 1976 Structure of root nodules formed by Rhizobium on the non-legume Trema cannabina var. scabra. Arch. Microbiol. 108, 159-166.

Verma D P S and Nadler K 1984 Legume-Rhizobium symbiosis: Host's point of view. In Plant Gene Research: Genes Involved in Microbe-Plant Interactions. Eds. D P S Verma and T H Hohn. pp 58-93. Springer-Verlag, New York.

Wang T L, Wood E A and Brewin N J 1982 Growth regulators, Rhizobium, and nodulation in peas. Planta 155 , 345-349.

Wilde M H 1953 Anatomical modifications of bean roots following treatment with 2,4-D. Am. J. Bot. 38, 79-91

Yatazawa M, Furuhashi A and Shimizu M 1967 Growth of callus tissue from rice root in vitro. Plant Cell Physiol. 8, 363-373.

Zeman A, Tchan Y T and Kennedy I R 1991 The paranodule on wheat as a model of a $\mathrm{N}_{2}$-fixing symbiosis on a non-legume. Proc. 9th Aust. Nitrogen Fixation Conf. 9, $80-81$.

Section editor: $R O D$ Dixon 